\title{
The Isoquinolone Derived Prolyl Hydroxylase Inhibitor ICA Is a Potent Substrate of the Organic Anion Transporters 1 and 3
}

\author{
Kei Schulz ${ }^{a}$ Yohannes Hagos $^{a}$ Gerhard Burckhardt ${ }^{a}$ Gunnar Schley ${ }^{b}$ \\ Nikolai Burzlaff ${ }^{c}$ Carsten Willam ${ }^{b}$ Birgitta C. Burckhardt ${ }^{a}$ \\ ${ }^{a}$ Institute of Systemic Physiology and Pathophysiology, University Medical Center Göttingen, Göttingen, \\ ${ }^{b}$ Department of Nephrology and Hypertension, University Medical Center Erlangen and 'Department of Inorganic \\ Chemistry and Organometallic Chemistry, Friedrich-Alexander-University, Erlangen, Germany
}

\section{Key Words}

Hypoxia $\cdot$ Renal proximal tubule $\cdot$ Drugs

\begin{abstract}
Objective: Many cellular responses to hypoxia are mediated by the transcription factor complex hypoxia-inducible factor (HIF). HIF stability is governed by a family of dioxygenases called HIF prolyl hydroxylases (PHDs). Isoquinolone-derived PHD inhibitors, like 2-(1-chloro-4-hydroxyisoquinoline3-carboxamido) acetate (ICA), which stabilize the intracellular HIF-a have been suggested as a potentially beneficial therapeutic strategy for the treatment of disorders associated with ischemia. To stabilize HIF- $a$, ICA has to be taken up into proximal tubule cells (PCTs) across the basolateral membrane by one of the organic anion transporters 1,2 or 3 (OAT1, OAT2 or OAT3). The release into the urine across the luminal membrane may be mediated by OAT4. Method: To demonstrate interaction of ICA with human OAT1, OAT2, OAT3 and OAT4, ICA was tested on these transporters stably transfected in HEK293 cells by using p-aminohippurate $(P A H), c G M P$ and estrone-3-sulfate (ES) as reference substrates, respectively. Results: Uptakes of PAH and ES in OAT1- and OAT3-transfected HEK293 cells were inhibited by ICA with half-maximal inhibition values of $0.29 \pm 0.05$ and $2.58 \pm 0.16 \mu \mathrm{M}$, respectively. OAT2 was less sensitive to ICA. Efflux experiments identified ICA as an OAT1 and OAT3 sub-
\end{abstract}

strate. Preloading OAT4-transfected HEK293 cells with ICA stimulated ES uptake by $18.3 \pm 3.8 \%$. Conclusion: The uptake of ICA across the basolateral membrane of PCTs occurs mainly by OAT1 and the efflux into the tubular lumen by OAT4.

(c) 2015 S. Karger AG, Basel

\section{Introduction}

Renal ischemia is known to play an important role in the pathophysiology of acute kidney injury as well as in chronic kidney disease. The balance between hypoxia and normoxia is regulated by transcription factors, commonly named hypoxia-inducible factors (HIFs). Under normoxic conditions, constitutively expressed HIF- $a$ subunits are hydroxylated by prolyl hydroxylases (PHDs) which leads to recognition and ubiquitination by the E3 ubiquitin ligase von Hippel-Lindau protein and subsequent degradation by the proteasome. Under hypoxia, hydroxylation does not occur due to the lack of molecular oxygen and HIF can accumulate in the cell. In the nucleus, HIF- $\alpha$ dimerizes with the HIF- $\beta$ /aryl hydrocarbon receptor nuclear receptor subunit and induces the transcription of its target genes $[1,2]$. HIF target genes are numerous, including enzymes of the glycolytic pathway, vascular endothelial growth factor and PHDs. PHDs are increasingly considered as promising therapeutic targets

\section{KARGER 125}

(c) 2015 S. Karger AG, Basel

$1660-8151 / 15 / 1314-0285 \$ 39.50 / 0$

E-Mail karger@karger.com

www.karger.com/nef
Prof. Birgitta C. Burckhardt

Institute of Systemic Physiology and Pathophysiology

University Medical Center Göttingen

Humboldtallee 23, DE-37073 Göttingen (Germany)

E-Mail birgitta.burckhardt @ med.uni-goettingen.de 
Fig. 1. Chemical structures of NOG and ICA. Structures were constructed by the free version of ChemSketch. Note that another nomenclature for ICA is 2-(1-chloro4-hydroxyisoquinoline-3-carboxamido) acetic acid. ICA was originally synthesized by HOECHST as $\$ 950086$ and later by FibroGen as FG-2216.

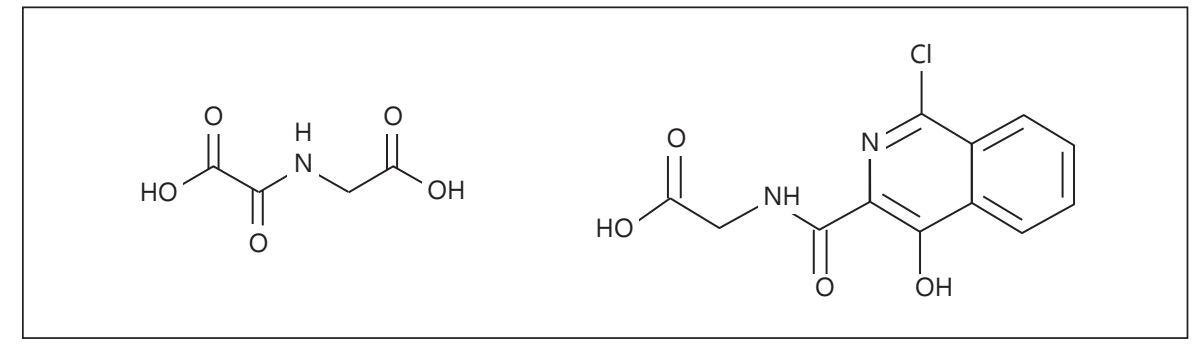

to improve kidney function in acute or chronic hypoxia $[3,4]$. Recently, we showed that the 2-oxoglutarate (2$\mathrm{OG}$ ) analogues, $\mathrm{N}$-oxalylglycine (NOG) and pyridine-2,4dicarboxylic acid, were transported by the organic anion transporter 1 (OAT1) and thus enter proximal tubule cells (PCTs) and stabilize HIF-1a [5]. Two-(1-chloro4-hydroxyisoquinoline-3-carboxamido) acetic acid (ICA, FG-2216) is another promising drug in establishing renal function after acute kidney injury in animal models $[6,7]$ and has also been shown to improve erythropoietin production in healthy volunteers and patients suffering from end-stage renal disease [8]. Since ICA is structurally related to NOG (fig. 1), we investigated whether this drug is a substrate for one of the OATs. OATs are potent drug transporters occurring preferentially in PCTs and transport a wide variety of structurally unrelated compounds such as antivirals, anti-neoplastics, non-steroidal anti-inflammatory drugs, $\beta$-lactam antibiotics, diuretics, sartanes as well as metabolite intermediates and endogenous compounds such as flavonoids or coumarins [9-12].

\section{Concise Methods}

\section{Reagents and Chemicals}

All chemicals were of analytical grade and were purchased from Sigma-Aldrich (Taufkirchen, Germany) or AppliChem (Darmstadt, Germany). The $\left[{ }^{3} \mathrm{H}\right]$-labeled compounds, p-aminohippurate (PAH), cGMP and estrone-3-sulfate (ES), were from Perkin Elmer (Rodgau, Germany). ICA was synthesized as described in Schley et al. [6].

\section{Cell Culture and Transport Experiments}

OAT1-, OAT2-, OAT3-, OAT4- and vector-transfected HEK293 cells are used routinely in our laboratory and were prepared and treated as described previously $[5,13]$. For transport measurements, cells were incubated at room temperature in Mammalian Ringer (MRi) that contained the $\left[{ }^{3} \mathrm{H}\right]$ nuclide at the concentration indicated in the respective figure legend and various experimental conditions. ICA was dissolved in DMSO. Uptake was terminated at $5 \mathrm{~min}$ by removal of the radio-labeled medium and immediately washing 3 times with ice-cold PBS. Cells were dissolved in $0.5 \mathrm{ml} 1 \mathrm{~N} \mathrm{NaOH}$ by gently shaking for $120 \mathrm{~min}$, and the $\left[{ }^{3} \mathrm{H}\right]$-content was determined by liquid scintillation counting (Tricarb 2810, Perkin Elmer). Protein quantification was performed by the Bradford assay [14].

\section{Statistics and Calculations}

Data are provided as means \pm SD. Unpaired 1-tailed Student's $t$ tests were used to show statistical significant differences for the inhibition of the uptake of PAH, cGMP or ES by ICA or by transstimulation of ICA on OAT1-, OAT3-, OAT4- and vector-transfected HEK293 cells. Statistical significance was set to *** at $\mathrm{p}<$ 0.001. The constants for half-maximal inhibition $\left(\mathrm{IC}_{50}\right)$ of $\mathrm{PAH}$, cGMP and ES uptake by ICA were calculated using SigmaPlot software (Systat Software, San Jose, Calif., USA).

\section{Results}

In OAT1-, OAT2- and OAT3-expressing HEK293 cells, ICA at a concentration of $100 \mu \mathrm{M}$ reduced the uptake of the reference substrate PAH for OAT1, cGMP for OAT2 and ES for OAT3 from $2.31 \pm 0.46,0.232 \pm 0.052$ and $0.034 \pm$ $0.052 \mathrm{pmol} \cdot \mathrm{mg}^{-1} \cdot \mathrm{min}^{-1}$ to $0.104 \pm 0.038,0.126 \pm 0.030$ and $0.006 \pm 0.001 \mathrm{pmol} \cdot \mathrm{mg}^{-1} \cdot \mathrm{min}^{-1}$, respectively. Inhibitors of OAT1 (probenecid), OAT2 (indomethacin) and OAT3 (probenecid), all at concentrations of $100 \mu \mathrm{M}$, inhibited uptake of PAH by 94.8 , of cGMP by 96.6 and of ES by $78.5 \%$, respectively (fig. 2a). A detailed analysis revealed $\mathrm{IC}_{50}$ values for the inhibition of uptake of PAH, cGMP and ES by ICA of $0.29 \pm 0.05,158.4 \pm 22.2$ and $2.58 \pm 0.16 \mu \mathrm{M}$, respectively, identifying ICA as a potent OAT1 and OAT3 inhibitor (fig. 2b). Competitive inhibition of PAH uptake by ICA in OAT1-transfected HEK293 cells was shown by a Dixon plot with a $K_{i}$ value of $1.17 \pm 0.28 \mu \mathrm{M}$ (fig. $2 c$ ). The competitive inhibition suggested that ICA was a substrate of OAT1. Therefore, OAT1- and vector-transfected HEK293 cells were incubated for $20 \mathrm{~min}$ in $0.5 \mu \mathrm{M}\left[{ }^{3} \mathrm{H}\right]$ $\mathrm{PAH}$ to achieve an equilibrium between intra- and extracellular PAH. By replacing $0.5 \mu \mathrm{M}\left[{ }^{3} \mathrm{H}\right] \mathrm{PAH}$ by $0.05 \mu \mathrm{M}$ $\left[{ }^{3} \mathrm{H}\right] \mathrm{PAH}$ and by $0.05 \mu \mathrm{M}\left[{ }^{3} \mathrm{H}\right] \mathrm{PAH}$ plus $10 \mu \mathrm{M} \mathrm{ICA}$, this equilibrium was disturbed and changes in the cellular $\left[{ }^{3} \mathrm{H}\right]$ PAH content were followed as a function of time (fig. 2d). Whereas, in vector-transfected HEK293 cells only a mar- 


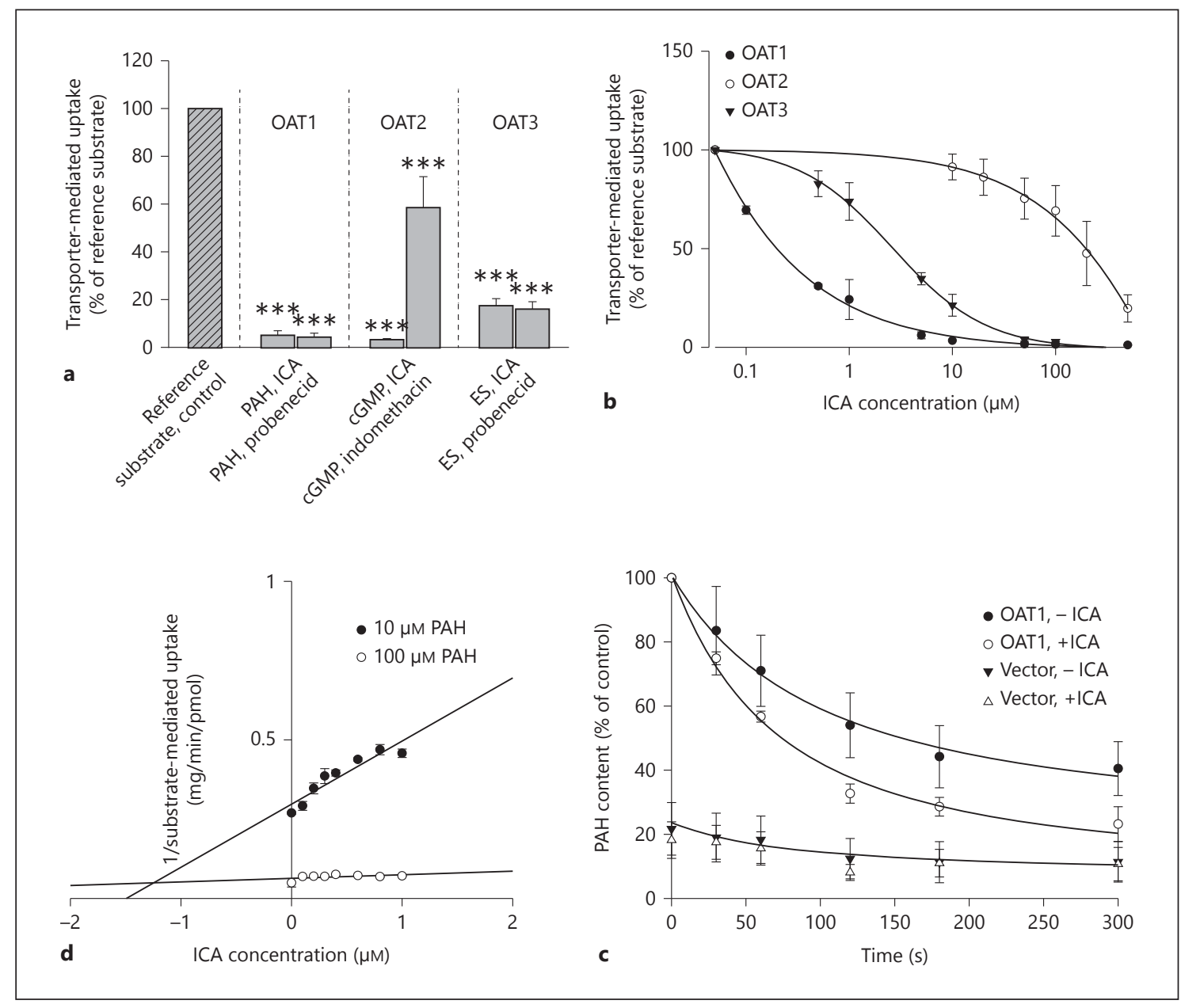

Fig. 2. Effect of ICA on OAT1-, OAT2- and OAT3-transfected HEK293 cells. a Inhibition of transporter-mediated substrate uptake by ICA. The 5-minute uptake of $0.5 \mu \mathrm{M}\left[{ }^{3} \mathrm{H}\right] \mathrm{PAH}$, of $100 \mathrm{nM}\left[{ }^{3} \mathrm{H}\right]$ cGMP plus $9.9 \mu \mathrm{M}$ un-labeled cGMP and of $\left.10 \mathrm{nM} \mathrm{[}{ }^{3} \mathrm{H}\right] \mathrm{ES}$ in OAT1-, OAT2- and OAT3-transfected HEK293 cells (dark grey columns) was inhibited by $100 \mu \mathrm{M} \mathrm{ICA}$ and by the transporter-specific inhibitors: probenecid $(100 \mu \mathrm{M})$ for OAT1 and OAT3 and indomethacin $(100 \mu \mathrm{M})$ for OAT2. The uptake obtained in vector-transfected HEK293 cells was subtracted from the uptake in transporter-transfected cells to obtain the transporter-mediated uptake. For a better comparison of the data, the uptake of the respective reference substrate was set to $100 \%$. $\mathbf{b}$ Determination of $\mathrm{IC}_{50}$ for the inhibition of substrate-mediated uptake by ICA. Plots were obtained by using 0.5 $\mu \mathrm{M}\left[{ }^{3} \mathrm{H}\right] \mathrm{PAH}(\bigcirc), 100 \mathrm{nM}\left[{ }^{3} \mathrm{H}\right] \mathrm{cGMP}$ plus $9.9 \mu \mathrm{M}$ un-labeled cGMP $(\boldsymbol{\nabla})$ and $10 \mathrm{nM}\left[{ }^{3} \mathrm{H}\right] \mathrm{ES}(\mathrm{O})$ and increasing concentrations of ICA. For better comparison, the uptake in the absence of ICA was set to

ginal ICA-independent decrease of the intracellular $\left[{ }^{3} \mathrm{H}\right]$ PAH content was noticed, OAT1-transfected HEK293 cells responded with a more rapid decrease of cellular $\mathrm{PAH}$ in the presence of ICA than in its absence, indicating uptake of ICA in exchange against $\left[{ }^{3} \mathrm{H}\right] \mathrm{PAH}$ by OAT1. Simi-
$100 \%$ (hatched bar). c Dixon plot to determine competitive inhibition of PAH uptake by ICA in OAT1-transfected HEK293 cells. Each line represents a linear regression analysis using $2 \mathrm{PAH}$ concentrations $(0: 10 \mu \mathrm{M} ; \mathrm{O}: 100 \mu \mathrm{M})$. From the intercept, a $\mathrm{K}_{\mathrm{i}}$ value of $1.17 \pm$ $0.28 \mu \mathrm{M}$ was obtained. $\mathbf{d}$ Efflux of PAH in OAT1- and vector-transfected HEK293 cells in the absence and presence of ICA as a function of time. Cells were incubated for $20 \mathrm{~min}$ at $37^{\circ} \mathrm{C}$ with $0.5 \mu \mathrm{M}\left[{ }^{3} \mathrm{H}\right]$ $\mathrm{PAH}$. After washing, cells were incubated for the time indicated in MRi containing $0.05 \mu \mathrm{M}\left[{ }^{3} \mathrm{H}\right] \mathrm{PAH}$ in the absence (OAT1: $\bullet$; vector: $\nabla)$ or presence of $10 \mu \mathrm{M} \mathrm{ICA}(\mathrm{OAT} 1: \mathrm{O}$; vector: $\Delta$ ). After the indicated time, the cellular content of $\left.{ }^{3} \mathrm{H}\right] \mathrm{PAH}$ was determined. Efflux of $\left[{ }^{3} \mathrm{H}\right] \mathrm{PAH}$ in OAT1-transfected HEK293 cells was larger in the presence of ICA $(O)$ than in its absence $(-)$ and was independent of ICA $(\boldsymbol{\nabla}, \Delta)$ in vector-transfected cells. All data presented in $(\mathbf{a}-\mathbf{d})$ were obtained in triplicate on each of 3 different cell passages and statistical significance in (a) was set at ${ }^{* * *} \mathrm{p}<0.001$. 


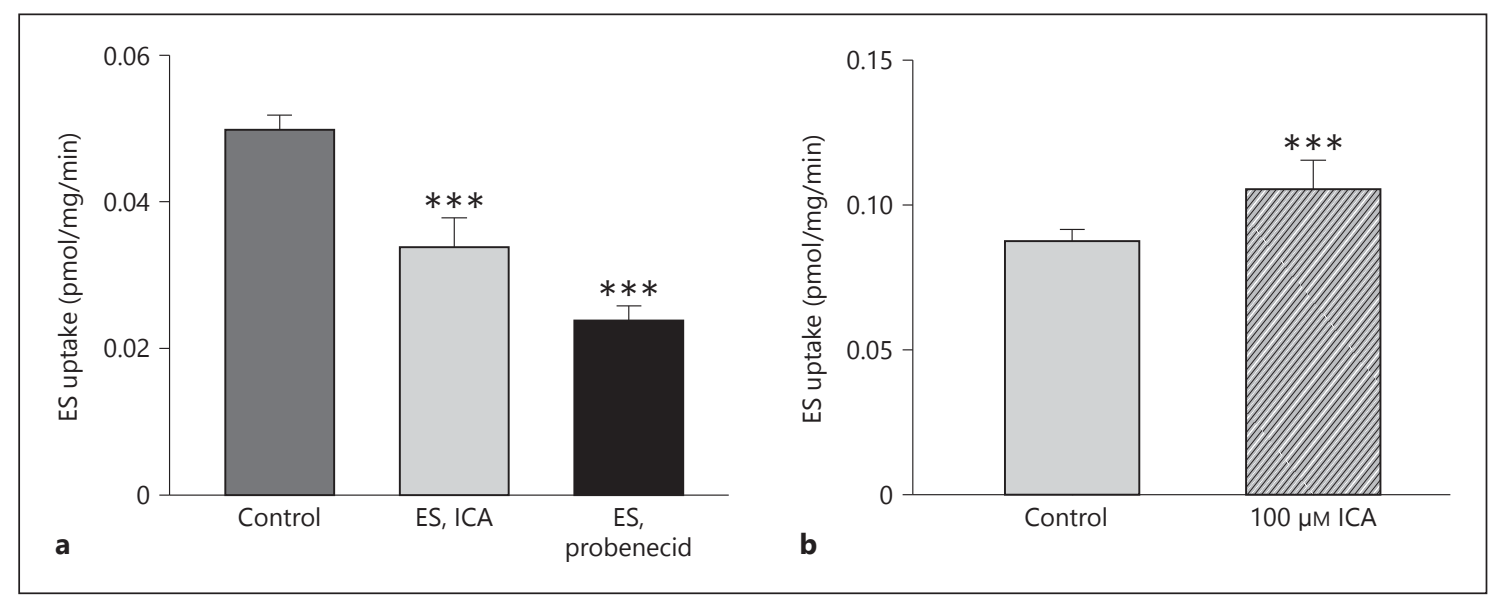

Fig. 3. Interaction of ICA with OAT4. a Inhibition of OAT4-mediated ES uptake by ICA. The 5-minute uptake of $10 \mathrm{nM}\left[{ }^{3} \mathrm{H}\right] \mathrm{ES}$ in OAT4-transfected HEK293 cells (dark grey columns) was inhibited by $100 \mu \mathrm{M}$ ICA (grey columns) and by probenecid $(100 \mu \mathrm{M}$, black columns). b Preloading of OAT4- and vector-transfected HEK293 cells with ICA. Cells were preloaded for $120 \mathrm{~min}$ at $37^{\circ} \mathrm{C}$ with either $220 \mu \mathrm{l} 0.1 \%$ DMSO in DMEM or $220 \mu \mathrm{l} 100 \mu \mathrm{M} \mathrm{ICA}$, $0.1 \%$ DMSO in DMEM. After extensive washings in PBS, the

Preloading resulted in an uptake of ES enhanced by $26.7 \pm$ $9.3 \%$ by ICA (measurements in triplicate on 3 subsequent cell preparations, $\mathrm{p}<0.001)$. The uptake in vector-transfected cells was not influenced by preloading the cells with ICA (0.004 $\mathrm{pmol} \cdot \mathrm{mg}^{-1} \cdot \mathrm{min}^{-1}$ in both preparations), excluding unspecific effects of ICA, which may induce additional substrate uptake (data not shown).

Whereas OAT1, OAT2 and OAT3 are localized in the basolateral membrane, OAT4 is found in the luminal membrane of PCTs. The uptake of ES by OAT4 was only moderately inhibited by ICA $(100 \mu \mathrm{M}$; fig. 3a); ES uptake decreased from $0.050 \pm 0.002$ to $0.034 \pm 0.004 \mathrm{pmol}$. $\mathrm{mg}^{-1} \cdot \mathrm{min}^{-1}$ in the presence of $100 \mu \mathrm{M}$ ICA. To test whether ICA interacts from the intracellular side with OAT4, OAT4- and vector-transfected HEK293 cells were preloaded for $120 \mathrm{~min}$ at $37^{\circ} \mathrm{C}$ with $100 \mu \mathrm{M}$ ICA and subsequently the uptake of ES was measured for $5 \mathrm{~min}$. This experimental design stimulated ES uptake in OAT4transfected cells by $18.3 \pm 3.8 \%$ from $0.088 \pm 0.004$ to $0.106 \pm 0.010 \mathrm{pmol} \cdot \mathrm{mg}^{-1} \cdot \mathrm{min}^{-1}$ (fig. 3b).

\section{Discussion}

Stabilization of HIF-1 $\alpha$ by inhibition of PHDs is considered a potential therapy for anemia and renal ischemia. There exist 3 isoforms of the HIF PHD enzyme: 5-minute uptake of $10 \mathrm{nM}\left[{ }^{3} \mathrm{H}\right] \mathrm{ES}$ in OAT4- and vector-transfected HEK293 cells was measured. Thereafter the cells were treated as described above for the uptake of the radio-labeled substrate. The uptake in vector-transfected cells was low and independent of the preloading treatment (data not shown). Columns represent mean values of experiments obtained in triplicate on each of 3 different cell passages; ${ }^{* * *} \mathrm{p}<0.001$.

PHD1, PHD2 and PHD3 [10]. PHDs are members of the dioxygenase family that require oxygen, iron and the tricarboxylic acid intermediate 2-OG for their catalytic activity. Among the PHDs, PHD2 is considered the most important one, because PHD2 knock-out mice are not viable and die between embryonic day 12.5 and 14.5 [3]. PHD2 is present mainly in the cytoplasm and has a substrate preference for HIF- $1 \alpha[15,16]$. PHD inhibitors derived from 2-OG bind, similar to 2-OG, at the catalytic site of the enzyme as a substrate mimic [3]. A potent PHD2 inhibitor is ICA (FG-2216). Its inhibitory activity against the PHD2 enzyme was determined to be $0.3 \mu \mathrm{M}$ [17] or $3.9 \mu \mathrm{M}$ [18], depending on the assay used.

The first step in renal secretion of organic anions is their uptake across the basolateral membrane of PCTs by one of the OATs (OAT1, OAT2 or OAT3). Since we recently identified NOG [5] as an OAT1 substrate, we speculated that ICA, due to its structural similarity to NOG, is also an OAT1 substrate. ICA turned out to be a very potent inhibitor of PAH uptake in OAT1-transfected HEK293 cells, exhibiting an $\mathrm{IC}_{50}$ of $0.29 \pm 0.05 \mu \mathrm{M}$. In the former study, the $\mathrm{IC}_{50}$ for NOG was determined to be $79.6 \pm 10.2 \mu \mathrm{M}$ [5], that is, the $\mathrm{IC}_{50}$ for ICA is approximately 275 times smaller than the $\mathrm{IC}_{50}$ for NOG in a similar experimental setup. The $\mathrm{IC}_{50}$ of ICA for the inhibition of the uptake of ES in OAT3-transfected HEK293 cells was $2.58 \pm 0.16 \mu \mathrm{M}$. Both $\mathrm{IC}_{50}$ values are in the range 
of the plasma concentration of ICA (approximately 3-5 $\mu \mathrm{M})$, which can be calculated from the maximal plasma concentration $\left(C_{\max } 179 \pm 31 \mu \mathrm{g} / \mathrm{ml}\right)$ given by Bernhardt et al. [8]. Efflux- or trans-stimulation experiments identified ICA as an OAT1 and an OAT3 substrate. However, due to the low stimulation of ES uptake by preloading OAT3-transfected cells with ICA, the contribution of OAT3 to ICA uptake may be low.

Whereas ICA is taken up primarily by OAT1, its release into the final urine is likely to be mediated by OAT4. In addition, ICA filtered by the glomerulus is able to block ES uptake by OAT4. The cooperation between inhibition by and transport of ICA by OAT4 may modulate intracellular ICA concentrations, thereby contributing to the beneficial effect of ICA on stabilizing HIF-1 $\alpha$. Beneficial effects of ICA were already demonstrated in mouse models of renal ischemia reperfusion injury, where application of ICA improved kidney structure and preserved renal function [6]. In a phase 1 study, ICA was applied orally to 12 hemodialysis patients, 6 of them anephric and 6 healthy volunteers [8]. The area under the curve was $3,660 \pm 813$ in healthy volunteers and increased to $5,730 \pm 2,420$ and $6,572 \pm$ $2,349 \mathrm{~h} / \mu \mathrm{g}$ per $\mathrm{ml}$ in nephric and anephric patients. Similarly, the $\mathrm{T}_{1 / 2}$ changed from $15.7 \pm 1.1$ to $29.8 \pm 11.4$ and $33.3 \pm 8.4 \mathrm{~h}$ in the same cohorts [8], and an increase in erythropoietin production in all subjects was observed. The increase in the area under the curve and in $\mathrm{T}_{1 / 2}$ in anephric patients highlights the role of renal secretion of ICA, a process in which OATs are likely to be involved.

\section{Acknowledgments}

The authors wish to thank Sören Petzke for skillful technical assistance.

\section{Disclosure Statement}

No conflict of interest exists. Y. Hagos is a Professor of Physiology at the Institute of Systemic Physiology and Pathophysiology at the University Medical Center Göttingen and also CEO and shareholder of PortaCellTec Biosciences GmbH.

\section{References}

1 Bishop T, Ratcliffe PJ: Signaling hypoxia by hypoxia-inducible factor protein hydroxylases: a historical overview and future perspectives. Hypoxia 2014;2:197-213.

-2 Semenza GL: Hypoxia-inducible factor 1 (HIF-1) pathway. Sci STKE 2007;2007:cm8.

3 Rabinowitz MH: Inhibition of hypoxia-inducible factor prolyl hydroxylase domain oxygen sensors: tricking the body into mounting orchestrated survival and repair responses. J Med Chem 2013;56:9369-9402.

-4 Selvaraju V, Parinandi NL, Adluri RS, Goldman JW, Hussain N, Sanchez JA, Maulik N: Molecular mechanisms of action and therapeutic uses of pharmacological inhibitors of HIF-prolyl 4-hydroxylases for treatment of ischemic diseases. Antioxid Redox Signal 2014;20:2631-2665.

5 Hagos Y, Schley G, Schödel J, Krick W, Burckhardt G, Willam C, Burckhardt BC: $\alpha$-Ketoglutarate-related inhibitors of HIF prolyl hydroxylases are substrates of renal organic anion transporters 1 (OAT1) and 4 (OAT4). Pflugers Arch 2012;464:367-374.

-6 Schley G, Klanke B, Schödel J, Kröning S, Türkoglu G, Beyer A, Hagos Y, Amann K, Burckhardt BC, Burzlaff N, Eckardt KU, Willam C: Selective stabilization of HIF-1 $1 \alpha$ in renal tubular cells by 2 -oxoglutarate analogues. Am J Pathol 2012;181:1595-1606.

7 Wang Z, Schley G, Türkoglu G, Burzlaff N, Amann KU, Willam C, Eckardt KU, Bern- hardt WM: The protective effect of prolyl-hydroxylase inhibition against renal ischaemia requires application prior to ischaemia but is superior to EPO treatment. Nephrol Dial Transplant 2012;3:929-936.

8 Bernhardt WM, Wiesener MS, Scigalla P, Chou J, Schmieder RE, Günzler V, Eckardt $\mathrm{KU}$ : Inhibition of prolyl hydroxylases increases erythropoietin production in ESRD. J Am Soc Nephrol 2010;21:2151-2156.

-9 Burckhardt G: Drug transport by organic anion transporters (OATs). Pharmacol Ther 2012;136:106-130.

10 Pelis RM, Wright SH: Renal transport of organic anions and cations. Compr Physiol 2011;1:1795-1835.

-11 Emami Riedmaier A, Nies AT, Schaeffeler E, Schwab M: Organic anion transporters and their implications in pharmacotherapy. Pharmacol Rev 2012;64:421-449.

12 VanWert AL, Gionfriddo MR, Sweet DH: Organic anion transporters: discovery, pharmacology, regulation and roles in pathophysiology. Biopharm Drug Dispos 2010;31:1-71.

13 Schwob E, Hagos Y, Burckhardt G, Burckhardt BC: Transporters involved in renal excretion of N-carbamoylglutamate, an orphan drug to treat inborn n-acetylglutamate synthase deficiency. Am J Physiol Renal Physiol 2014;307:F1373-F1379.

14 Bradford MM: A rapid and sensitive method for the quantitation of microgram quantities of protein utilizing the principle of proteindye binding. Anal Biochem 1976;72:248-254.

-15 Takeda K, Ho VC, Takeda H, Duan LJ, Nagy A, Fong GH: Placental but not heart defects are associated with elevated hypoxia-inducible factor alpha levels in mice lacking prolyl hydroxylase domain protein 2. Mol Cell Biol 2006;26:8336-8346.

16 Epstein AC, Gleadle JM, McNeill LA, Hewitson KS, O'Rourke J, Mole DR, Mukherji M, Metzen E, Wilson MI, Dhanda A, Tian YM, Masson N, Hamilton DL, Jaakkola P, Barstead R, Hodgkin J, Maxwell PH, Pugh CW, Schofield CJ, Ratcliffe PJ: C. elegans EGL-9 and mammalian homologs define a family of dioxygenases that regulate HIF by prolyl hydroxylation. Cell 2001;107:43-54.

17 Chowdhury R, Candela-Lena JI, Chan MC, Greenald DJ, Yeoh KK, Tian YM, McDonough MA, Tumber A, Rose NR, Conejo-Garcia A, Demetriades M, Mathavan S, Kawamura A, Lee MK, van Eeden F, Pugh CW, Ratcliffe PJ, Schofield CJ: Selective small molecule probes for the hypoxia inducible factor (HIF) prolyl hydroxylases. ACS Chem Biol 2013;8:14881496.

$>18$ Hong YR, Kim HT, Ro S, Cho JM, Lee SH, Kim IS, Jung YH: Discovery of novel 2-(2-(3-hydroxy-pyridin-2-yl)-thiazol-4-yl]-acetamide derivatives as HIF prolyl 4-hydroxylase inhibitors; SAR, synthesis and modeling evaluation. Bioorg Med Chem Lett 2014;24:3142-3145. 